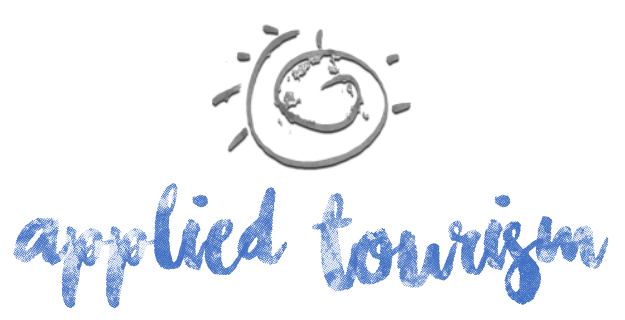

Volume 2, número 3, 2017, p. 26-36

\title{
A EDUCAÇÃO AMBIENTAL ATRAVÉS DO TURISMO PEDAGÓGICO
}

\author{
Aline Beatriz Pacheco Carvalho \\ Doutorado em Memória Social e Bens Culturais na Universidade La Salle \\ Bióloga no Centro de Estudos Ambientais Eco-Terrenão -Glorinha, RS \\ pacheco.carvalho@gmail.com \\ Letícia Orling Camacho Escobar \\ Mestrado em Avaliação de Impactos Ambientais \\ Bióloga no Centro de Estudos Ambientais Eco-Terrenão -Glorinha, RS \\ leticia3344@yahoo.com.br \\ Cristina Vargas Cademartori \\ Professora Adjunta II da Universidade La Salle \\ Memória Social e Bens Culturais \\ cristina.cademartori@unilasalle.edu.br
}

Recebido: 28 de junho, 2017

Aprovado: 27 de outubro, 2017

\section{RESUMO}

Atividades como viagens de estudos e visitas guiadas mostram-se efetivas ao despertar a atenção das pessoas para os problemas decorrentes da degradação do meio ambiente. Neste sentido, o turismo pedagógico, integrando educação e conservação da Natureza, parece ser uma estratégia positiva e capaz de contribuir para a transformação do sujeito a partir da sensibilização para as questões ambientais. Considerando este contexto, o trabalho tem como objetivo apresentar algumas propostas educativas resultantes de um projeto de turismo pedagógico que visou incorporar a educação ambiental em suas práticas. As ações ocorreram entre 2014 e 2017 na sede do Centro de Estudos Ambientais Eco-Terrenão, no município de Glorinha, Rio Grande do Sul. O turismo pedagógico pode, de fato, complementar a educação ambiental ao promover a integração do sujeito com a natureza, através do reconhecimento do meio e da percepção ambiental.

Palavras-chaves: Meio ambiente. Educação. Turismo. 


\section{(3) applied towrigen}

Volume 2, número 3, 2017, p. 26-36

Figura 1. Mapa temático da propriedade

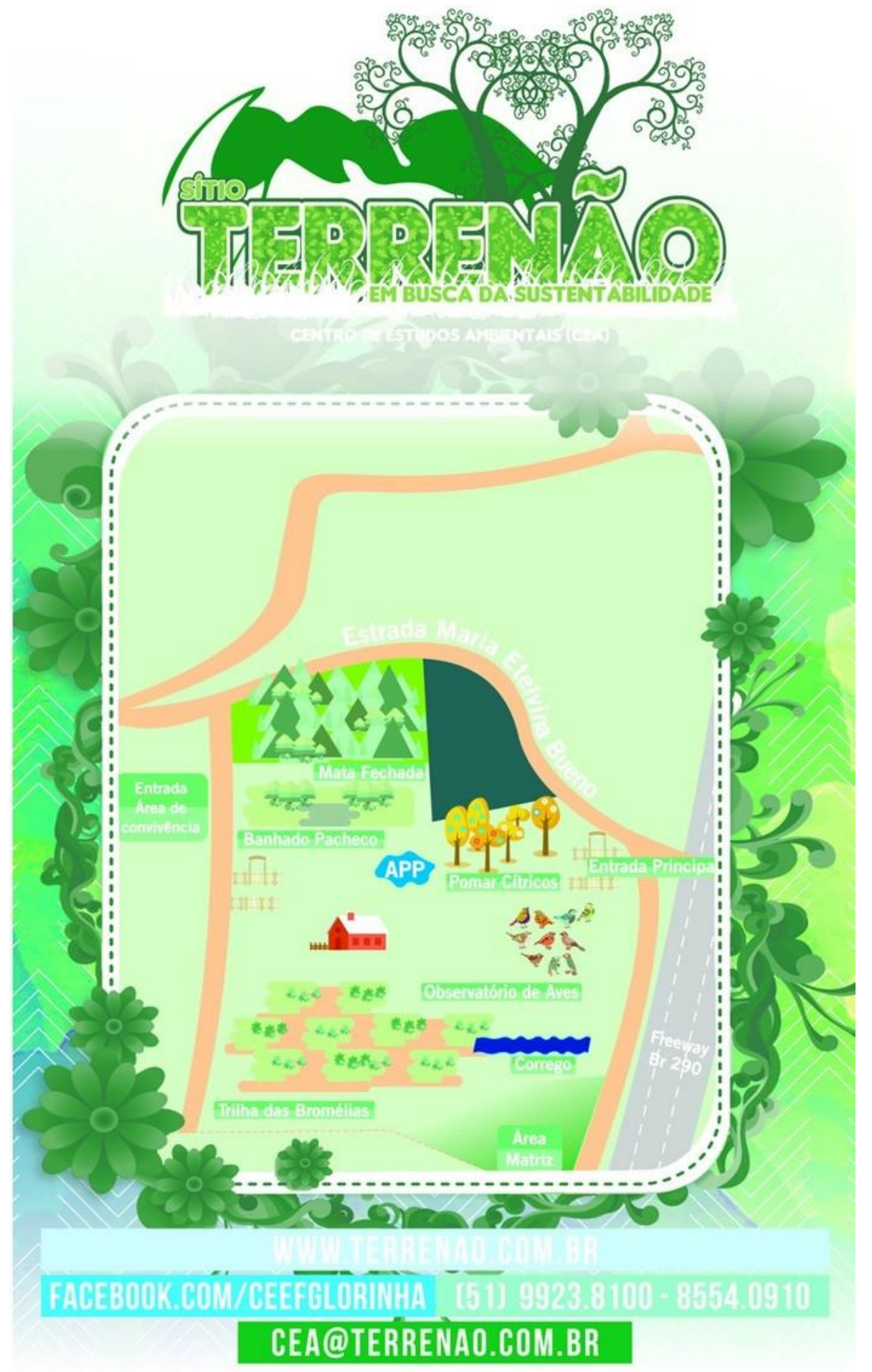

Fonte: autoras (2017). 


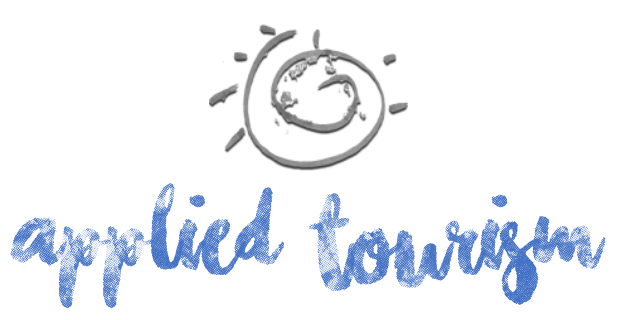

Volume 2, número 3, 2017, p. 26-36

\section{Das atividades desenvolvidas}

Durante o primeiro ano, após a implantação do Centro de Estudos Ambientais, as atividades concentraram-se em torno do diagnóstico sobre os principais agentes de perturbação da área, bem como da proposição de soluções pertinentes. Relativamente aos inventários e monitoramentos faunísticos e florísticos foram definidas as atividades de educação ambiental (figura 2) que seriam empregadas, considerando-se os seus respectivos propósitos e a relação com o turismo pedagógico.

Figura 2. Atividades de educação e sensibilização ambiental
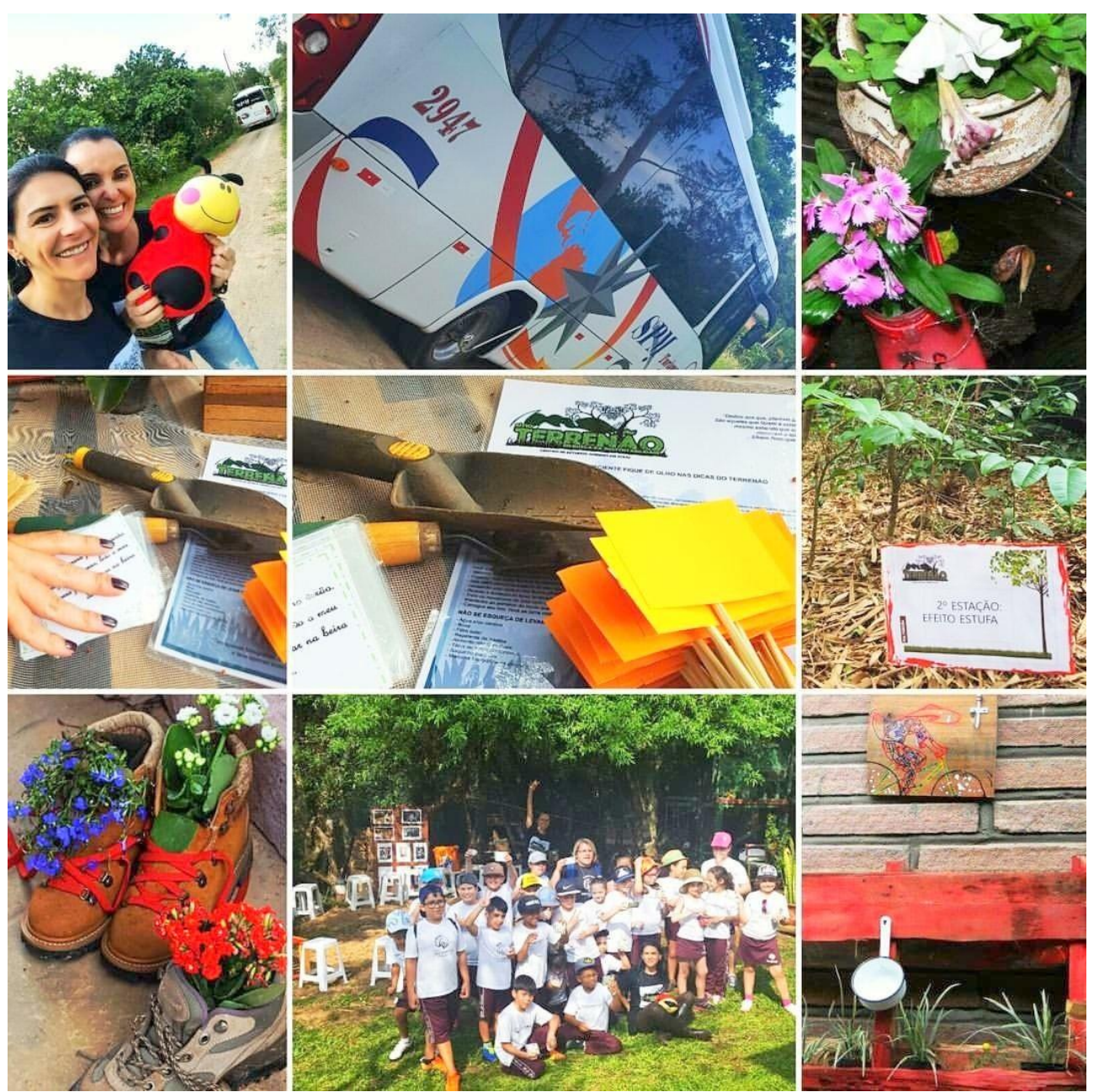

Fonte: autoras (2017). 


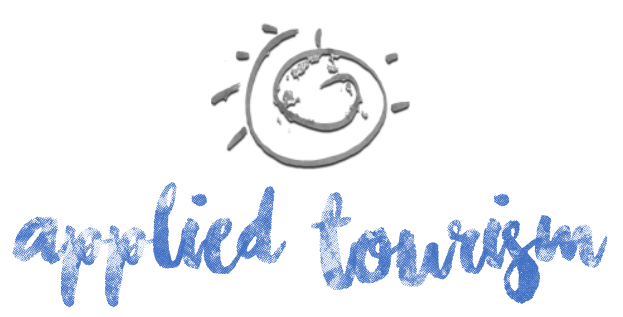

Volume 2, número 3, 2017, p. 26-36

Os temas norteadores e as respectivas atividades foram (ver tabela 1.):

1. acolhida no meio rural, que visou a recepção dos visitantes e a apresentação do Centro de Estudos Ambientais Eco-Terrenão, contextualizando sua criação e objetivos pedagógicos, bem como a apresentação do município de Glorinha e de alguns aspectos socioambientais;

2. realização de jogos pedagógicos sobre fauna e flora dos biomas do Rio Grande do Sul e suas principais ameaças, adaptados à faixa etária dos visitantes, com o objetivo de contribuir para o processo de ensino-aprendizagem;

3. caminhada por trilha interativa utilizada como ferramenta pedagógica para observação e interpretação de elementos significativos do ambiente;

4. observação da fauna e flora em pontos estratégicos da área, no intuito de aproximar os visitantes das diferentes espécies que ocorrem nos biomas característicos do município e estado;

5. plantio de mudas, com o propósito de apresentar os benefícios de um ambiente arborizado e destacar a importância de plantas nativas para a manutenção da integridade ecológica da região. 


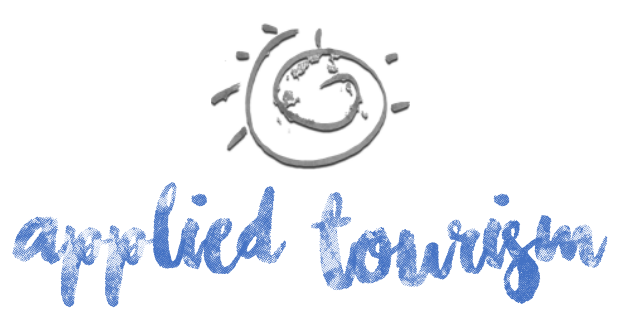

Volume 2, número 3, 2017, p. 26-36

Tabela 1. Atividades de educação ambiental.

\begin{tabular}{|c|c|c|}
\hline Propostas em Educação Ambiental & $x$ & Turismo Pedagógico \\
\hline 1. Acolhida no meio rural & & $\begin{array}{l}\text { Provocar o interesse do visitante para o novo } \\
\text { conhecimento, pelo local, pelos usos e costumes } \\
\text { da população (Ansarah, 2001). }\end{array}$ \\
\hline 2. Jogos pedagógicos & & $\begin{array}{l}\text { Despertar o senso analítico crítico e a vontade } \\
\text { de conhecer mais a respeito do assunto } \\
\text { abordado (Ansarah, 2001). }\end{array}$ \\
\hline 3. Trilha interpretativa & & $\begin{array}{l}\text { Estimular os sentidos e desenvolver a habilidade } \\
\text { de interpretação dos fenômenos naturais. }\end{array}$ \\
\hline 4. Observações da fauna e flora & & $\begin{array}{l}\text { Proporcionar o contato direto com a natureza e } \\
\text { sensibilizar para a temática da conservação } \\
\text { ambiental. }\end{array}$ \\
\hline $\begin{array}{l}\text { 5. Plantio de mudas nativas e/ou } \\
\text { hortaliças orgânicas }\end{array}$ & & $\begin{array}{l}\text { Aproximar o visitante do contexto local através } \\
\text { das práticas comuns da região (Ansarah, 2001) e } \\
\text { desenvolver o senso crítico sobre a realidade } \\
\text { cultural e ambiental, e sobre a necessidade do } \\
\text { cultivo sustentável de alimentos. }\end{array}$ \\
\hline
\end{tabular}

Fonte: autoras (2017).

\section{RESULTADOS}

Ao longo de três anos foram realizadas visitas orientadas ao público da educação básica e superior da Região Metropolitana de Porto Alegre, capital do Rio Grande do Sul, envolvendo cerca de 400 alunos/turistas/visitantes interessados em vivenciar experiências práticas sobre a temática rural e a conservação ambiental. Todas as visitas e atividades propostas (tabela 1) foram elaboradas a partir de pressupostos da educação ambiental, Biologia da Conservação e do turismo sustentável, que visam salvaguardar o ambiente e os recursos naturais a fim de garantir o crescimento potencial e econômico da atividade sem representar riscos de impactos negativos ao meio.

Os resultados desta experiência demonstram que é possível integrar educação ambiental e turismo pedagógico em uma estratégia capaz de vincular viagens e atividades em campo, e proporcionar aos alunos de todas as esferas do ensino uma vivência prazerosa e única. Este 


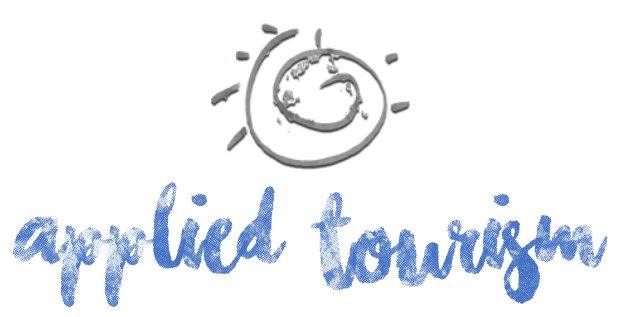

Volume 2, número 3, 2017, p. 26-36

outros, são elementos eficientes e complementares à educação formal, dos quais o turismo se apropria e pode, com legitimidade, respaldar os educadores quanto à elaboração de suas atividades extraclasse (Scremin \& Junqueira, 2012).

Desta forma, recomendam-se atividades semelhantes às desenvolvidas e relatadas neste artigo aos programas ou projetos de educação ambiental e turismo pedagógico que visem:

- $\quad$ conhecer e valorizar a cultura do meio rural;

- $\quad$ incentivar as escolas públicas e privadas a conhecerem a realidade local das suas respectivas regiões;

- aproximar o aluno do contexto local através das práticas comuns da região e desenvolver o senso crítico sobre a realidade cultural e ambiental;

- proporcionar aos estudantes o contato com a natureza e estimular o desenvolvimento de consciência crítica e postura cidadã por meio da vivência.

- $\quad$ aproximar os alunos das paisagens que caracterizam a região em que estão inseridos, destacando a biodiversidade local, principais impactos e a necessidade de ações de conservação.

\section{CONSIDERAÇÕES FINAIS}

O turismo pedagógico pode, de fato, complementar a educação ambiental ao promover a integração do sujeito com a natureza, através do reconhecimento do meio e da percepção ambiental. Consequentemente, a ampliação de parcerias com instituições de ensino da rede básica e superior é fundamental para consolidar ações que promovam o turismo pedagógico, a integração socioambiental e a educação ambiental. 


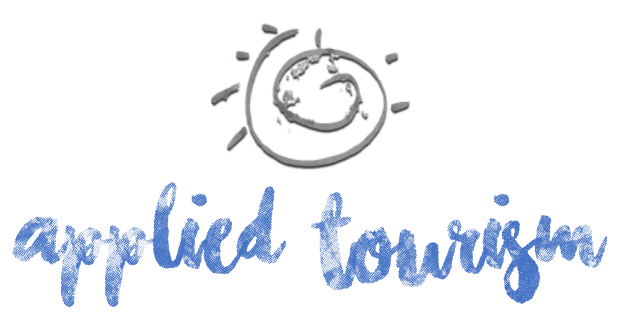

Volume 2, número 3, 2017, p. 26-36

\section{REFERÊNCIAS}

Ansarah, M. G. dos R. (2001). Teoria Geral do Turismo. In M. G. dos R. Ansarah (Org.), Turismo: como aprender, como ensinar. 40-52. São Paulo: SENAC.

Beni, M. C. (2002). Análise Estrutural do Turismo. São Paulo: SENAC.

Bittencourt, A; Brasileiro, I.; França, O. (2010). Artigos Acadêmicos. Ministério do Turismo Secretaria Nacional de Políticas de Turismo, Departamento de Estruturação, Articulação e Ordenamento Turístico, Coordenação-Geral de Segmentação. Turismo cívico: uma prática de cidadania na capital da república. Segmentação do turismo: experiências, tendências e inovações. 59-76. Brasília. Disponível em: http://www.turismo.gov.br/sites/default/turismo/o_ministerio/publicacoes/downloads_p ublicacoes/Segmentacao_Turismo_Experiencias_Tendencias_Inovacoes.pdf. Acesso em: 01 de ago. 2017.

Brasil, Ministério da Educação. (1996). Lei de Diretrizes e Bases - 9.394 de 1996. Disponível em: $<$ http://portal.mec.gov.br/seb/> . Acesso em: 27 jul. 2017.

Carvalho, I. C. de M. (2001). Qual educação ambiental? Elementos para um debate sobre educação ambiental e extensão rural. Agroecologia e Desenvolvimento Rural Sustentável. 2(2), 4351.

De Araújo, M. A. L. (2000). Transdisciplinaridade e Educação. Revista de Educação CEAP. 8, 7-19.

Gadotti, M. (2000). Pedagogia da Terra. São Paulo: Peirópolis.

Gomes, D. S.; Mota, K. M.; Perinotto, A. R. C. (2012). Turismo pedagógico como ferramenta de educação patrimonial: a visão dos professores de História em um colégio estadual de Parnaíba (Piauí, Brasil). Turismo \& Sociedade. 5(1), 82-103.

Perinotto, A. R. C. (2008). Turismo Pedagógico: uma ferramenta para educação ambiental. Caderno Virtual de Turismo. 8(1), 100-103.

Reigota, M. (2010). Meio ambiente e representação social. São Paulo: Cortez.

Rodrigues, E. (2002). Biologia da Conservação. Londrina: E. Rodrigues.

Rodrigues, E. (2013). Ecologia da Restauração. Londrina: Planta.

Scremin, J.; Junqueira, S. (2012). Aprendizado diferenciado: turismo pedagógico no âmbito escolar. CAD. Est. Pes. Tur. 1, 26-42. 